\title{
Association of HDL Cholesterol with In-Hospital Outcome of Patients with Acute Coronary Syndrome
}

Chowdhury Muhammad Omar Faruque ${ }^{1}$, Abdul Wadud Chowdhury², Miftaul Jannath Chowdhury ${ }^{3}$, Abu Thaher Mohammad Mahfuzul Hoque ${ }^{4}$, Md. Solaiman Mia ${ }^{5}$, SM Eftar Jahan Kabir6, Mofazzal Hossain ${ }^{7}$.

\begin{abstract}
:
Background:Acute coronary syndrome is a cardiac emergency. It is increasing dramatically and becoming a major burden in our health care system. Relation between serum lipid profile and acute coronary syndrome is well established. Our study tried to reveal association of high density lipoprotein cholesterol (HDL-C) with in-hospital outcome of patients with acute coronary syndrome. Methods: The study was a cross sectional comparative study. Clinical \& biochemical evaluation was done in hospital settings. A total number of 271 patients were included in the study and divided into two groups. Patients with low HDL-C level were in
\end{abstract}

group I and patients with normal HDL-C were in group II. Results: Group I populations had more complications \& more in- hospital stay than group II $(74.3 \%$ vs $28.9 \%$, $\mathrm{P}<0.001$ and $6.65 \pm 2.04$ days vs $5.09 \pm 1.44$ days, $\mathrm{p}<0.001$ respectively). Conclusion: The study revealed significant association of HDL-C with outcome of acute coronary syndrome patients. Complications of acute coronary syndrome were more in patients with low HDLC level.

Key words:Acute Coronary Syndrome, Ischemic Heart Disease, HDL Clesterol

(Bangladesh Heart Journal 2017; 32(2) : 114-118)

\section{Introduction:}

Coronary artery disease (CAD) has become a major health problem and is the most common cause of mortality and morbidity in the entire world ${ }^{1}$. Among the CAD, acute coronary syndrome (ACS) is the leading cause of death in developed countries and second leading cause of death in developing countries and by the year 2020, CAD will hold

1. Consultant, Upazila Health Complex, Golapgonj, Sylhet, Bangladesh.

2. Prof. and Head. Department of Cardiology, Dhaka Medical College, Dhaka, Bangladesh.

3. Department of Pharmacology, Sylhet Women's Medical College, Sylhet, Bangladesh.

4. Asst. Prof.Department of Cardiology, Dhaka Medical College, Dhaka, Bangladesh.

5. Consultant, Adhunik Sadar Hospital, Habiganj., Bangladesh.

6. Department of Cardiology, National Institute of Cardiovascular Disease, Bangladesh.

7. Upazila Health Complex, Madan, Netrokona, Bangladesh.

Address of correspondence: Dr. Chowdhury Muhammad Omar Faruque, Consultant, Upazila Health Complex, Golapgonj, Sylhet, Bangladesh, E-mail: dromarcard76@gmail.com, Cell: +88 01711617776 the first place in the WHO's list of leading cause of disability ${ }^{2}$. The progressively increasing trend of the disease in our country shows that the prevalence of CAD in our country was 3.3/1000 in 1976 and 17.2/1000 in 1986 indicating a 5 fold increase in 10 years. CAD is becoming a significant burden on health care services in Bangladesh ${ }^{3}$. It is a multifactorial disease involving well-known risk factors such as age, male sex, smoking, hypertension, diabetes mellitus, renal impairment, obesity, hypercholesterolemia, family history of premature CAD and sedentary life style ${ }^{4}$ Preexisting atherosclerotic plaque rupture with superimposed thrombosis in epicardial coronary arteries is by far the most frequent underlying cause of $\mathrm{ACS}^{5}$. There is consistent epidemiological and clinical evidence showing low HDL- cholesterol to be a strong independent risk factor for coronary heart disease (CHD), likely due to reverse cholesterol transport, anti-inflammatory and antioxidant effects of $\mathrm{HDL}^{6,7}$ Low HDL-cholesterol level is strongly associated with increased risk of in-hospital mortality and adverse cardiac events in patients with $\mathrm{ACS}^{8-11}$. Patients

DOI: http://dx.doi.org/10.3329/bhj.v32i2.36098

Copyright $\odot 2017$ Bangladesh Cardiac Society. Published by Bangladesh Cardiac Society. This is an Open Access articles published under the Creative Commons Attribution-NonCommercial 4.0 International License (CC BY-NC). This license permits use, distribution and reproduction in any medium, provided the original work is properly cited and is not used for commercial purposes. 
from South Asia have a distinct cardiovascular risk profile with profound health consequence. The genesis of this risk is multifactorial of which lower level of HDL-C is an important culprit. ${ }^{12}$ These observations emphasize the need for studies evaluating impact of low HDL-cholesterol on the outcome of hospitalized patients with ACS in Bangladesh. The aim of this study is to evaluate the association of HDL-C with inhospital outcome of ACS patients in our setting.

\section{Methods:}

This cross sectional comparative study was conducted at the Department of Cardiology, Dhaka Medical College Hospital from April 2011 to March 2012 with the objective to assess association of HDL cholesterol (HDL-C) with inhospital outcome of patients with acute coronary syndrome (ACS). Study population was all the patients with ACS admitted into the Department of Cardiology, Dhaka Medical College Hospital within the study period. Patients having previous history of ACS/Percutaneous Coronary Intervention/ Coronary Artery Bypass Grafting, cardiomyopathy, congenital heart disease, valvular heart disease and patients with serious co-morbid conditions were excluded. After fulfilling the inclusion and exclusion criteria index patients were included. Fasting serum lipid profile was measured within 24 hours of the event by standard procedure. Level of serum HDL-C was grouped as follows:

Group I: with HDL-C level

$\begin{array}{ll}\text { In male } & -<40 \mathrm{mg} / \mathrm{dl} \\ \text { In female } & -<50 \mathrm{mg} / \mathrm{dl}\end{array}$

Group II: with HDL-C level

$$
\begin{array}{ll}
\text { In male } & -\geq 40 \mathrm{mg} / \mathrm{dl} \\
\text { In female } & -\geq 50 \mathrm{mg} / \mathrm{dl}
\end{array}
$$

Patients were evaluated both clinically \& by investigation from the time of selection till discharge (giving more importance on rate, rhythm \& character of pulse and measuring blood pressure regularly; measuring serum electrolyte, serum troponin-I level, ECG monitoring \& echocardiographic findings). In-hospital outcomes of all the patients were evaluated as outcome variables (heart failure, arrhythmias, second degree/ third degree heart block, cardiogenic shock, duration of hospital stay and death).
Data was collected properly \& systematically analyzed by using SPSS version 12. Test statistics used to analyze the data were descriptive statistics, chi square and unpaired ttests. Level of significance was set at 0.05 .

\section{Results:}

There were no statistically significant difference between two groups regarding age, sex, traditional risk factors, clinical diagnosis \& family history. Distribution of patients was same. Regarding symptoms, presentation with chest pain between two groups was not significant $(p=0.068)$. However, significantly higher number of patients of group I presented with breathlessness than patients of group II $(P=0.001)$. Conversely, significantly more number of patients of group II presented with chest discomfort than patients of group I $(p=0.033)$. Type of myocardial infarction between two groups was not statistically significant. Heart rate of group I was significantly higher than group II $(p=0.005)$. Ejection fraction was significantly lower in group I than group II $(p=0.032)$. Regarding biochemical parameters, difference in fasting blood glucose \& serum creatinine was not statistically significant between two groups $(p=0.557 \& 0.797$ respectively).

In the contrary, serum troponin I concentration in group I was significantly higher than group II $(p=0.032)$. Mean serum total cholesterol and serum triglyceride were significantly more in group I than group $\|(p<0.001$ and $p=0.002$ respectively). Similarly mean LDL cholesterol was significantly more in group I than group II $(p=0.002)$.

However, mean HDL cholesterol was significantly less in group I than group II $(p<0.001)$. Regarding in- hospital outcomes, patients of group I significantly developed heart failure $(23.5 \%$ vs $8.9 \%, p=0.029)$, arrhythmia $(15.5 \%$ vs $4.4 \%, p=0.049)$ and cardiogenic shock $(12.4 \%$ vs $2.2 \%, p=$ $0.044)$ than group II. There is no statistically significant difference in mortality $(p=0.287)$, cardiac arrest $(p=0.631)$ \& heart block ( $p=0.409)$ between two groups. Group I patients stayed at hospital for significantly more days than group II patients $(p<0.001)$.

Table-I

Distribution of the study subjects according to different clinical presentation

\begin{tabular}{lcccc}
\hline Clinical presentation & & Groups & $p$ \\
& $\begin{array}{c}\text { Group I }(\mathrm{n}=226) \\
\mathrm{n}(\%)\end{array}$ & $\begin{array}{c}\text { Group II }(\mathrm{n}=45) \\
\mathrm{n}(\%)\end{array}$ & $\begin{array}{c}\text { Total }(\mathrm{n}=271) \\
\mathrm{n}(\%)\end{array}$ & 0.068 \\
\hline Chest pain & $148(65.5 \%)$ & $23(51.1 \%)$ & $171(63.1 \%)$ & 0.001 \\
Breathlessness & $76(33.6 \%)$ & $4(8.9 \%)$ & $80(29.5 \%)$ & 0.033 \\
Chest discomfort & $64(28.3 \%)$ & $20(44.4 \%)$ & $84(31.0 \%)$ & 0 \\
\hline
\end{tabular}


Table-II

Distribution of study subjects according to clinical diagnosis

\begin{tabular}{lcccc}
\hline Clinical diagnosis & \multicolumn{2}{c}{ Groups } & \\
\cline { 2 - 3 } & Group I $(\mathrm{n}=226)$ & Group II $(\mathrm{n}=45)$ & & Total $(\mathrm{n}=271)$ \\
$\mathrm{nn}(\%)$ & $\mathrm{n}(\%)$ & $\mathrm{n}(\%)$ & 0.914 \\
NSTEMI & $44(19.5 \%)$ & $10(22.2 \%)$ & $54(19.9 \%)$ & $142(52.4 \%)$ \\
STEMI & $119(52.7 \%)$ & $23(51.1 \%)$ & $75(27.7 \%)$ \\
Unstable angina & $63(27.9 \%)$ & $12(26.7 \%)$ & \\
\hline
\end{tabular}

NSTEMI=Non ST- segment elevation myocardial infarction.

STEMI= ST- segment elevation myocardial infarction.

Table-III

Distribution of the study subjects according to type of myocardial infarction

\begin{tabular}{|c|c|c|c|c|}
\hline \multirow[t]{2}{*}{ Type of MI } & \multicolumn{2}{|c|}{ Groups } & \multirow[b]{2}{*}{$\begin{array}{c}\text { Total }(n=196) \\
n(\%)\end{array}$} & \multirow[t]{2}{*}{$\mathrm{p}$} \\
\hline & $\begin{array}{c}\text { Group I }(n=163) \\
n(\%)\end{array}$ & $\begin{array}{c}\text { Group II }(n=33) \\
n(\%)\end{array}$ & & \\
\hline Anterior Ml & $93(57.1 \%)$ & $15(45.5)$ & $108(55.1 \%)$ & 0.381 \\
\hline Inferior MI without RV infarction & $40(24.5 \%)$ & $13(39.4 \%)$ & $53(27.0 \%)$ & 0.079 \\
\hline Inferior MI with RV infarction & $30(18.4 \%)$ & $5(15.1 \%)$ & $35(17.9 \%)$ & 0.656 \\
\hline
\end{tabular}

$\mathrm{MI}=$ Myocardial infarction, $\mathrm{RV}=$ Right ventricle

Table-IV

Distribution of the study subjects by traditional risk factors

\begin{tabular}{|c|c|c|c|c|}
\hline \multirow[t]{2}{*}{ Traditional risk factors } & \multicolumn{2}{|c|}{ Groups } & \multirow[b]{2}{*}{$\begin{array}{c}\text { Total }(n=271) \\
n(\%)\end{array}$} & \multirow[t]{2}{*}{$\mathrm{P}$} \\
\hline & $\begin{array}{c}\text { Group I }(n=226) \\
n(\%)\end{array}$ & $\begin{array}{c}\text { Group II }(n=45) \\
n(\%)\end{array}$ & & \\
\hline Smoking & $115(50.9 \%)$ & $30(66.7 \%)$ & $145(53.5 \%)$ & 0.053 \\
\hline Hypertension & $111(49.1 \%)$ & $19(42.2 \%)$ & $130(48.0 \%)$ & 0.398 \\
\hline Diabetes mellitus & $80(35.4 \%)$ & $18(40.0 \%)$ & $98(36.2 \%)$ & 0.557 \\
\hline Family history of CAD & $28(12.4 \%)$ & $10(22.2 \%)$ & $38(14.0 \%)$ & 0.083 \\
\hline Renal impairment (serum creatinine level $>1.4 \mathrm{mg} / \mathrm{dl}$ ) & $33(15.0 \%)$ & $3(7.0 \%)$ & $36(13.3 \%)$ & 0.152 \\
\hline
\end{tabular}

$\mathrm{CAD}=$ Coronary artery disease.

Table-V

Distribution of study subjects according to hemodynamic status ( $n=271)$

\begin{tabular}{lccc}
\hline Hemodynamic status & \multicolumn{2}{c}{ Groups } & P \\
\cline { 2 - 3 } & Group I $(\mathrm{n}=226)$ & Group II $(\mathrm{n}=45)$ & \\
& mean \pm SD & $81.33 \pm 10.95$ & 0.005 \\
\hline Pulse $($ beat/min) & $88.20 \pm 15.43$ & $127.82 \pm 18.45$ & 0.599 \\
SBP $(\mathrm{mmHg})$ & $130.12 \pm 26.02$ & $77.77 \pm 11.69$ & 0.254 \\
DBP $(\mathrm{mmHg})$ & $80.66 \pm 14.95$ & $51.25 \pm 9.0$ & 0.032 \\
Ejection fraction $(\%)$ & $45.17 \pm 11.47$ & & \\
\hline
\end{tabular}

SBP-Systolic blood pressure, DBP-Diastolic blood pressure. 
Table-VI

Distribution of study subjects according to fasting lipid profile $(n=271)$

\begin{tabular}{lccc}
\hline Fasting lipid profile & \multicolumn{2}{c}{ Groups } & $\mathrm{P}$ \\
\cline { 2 - 3 } & Group I(n=226) & Group II $(\mathrm{n}=45)$ & \\
\hline mean \pm SD & $184.39 \pm 47.43$ & $151.91 \pm 43.25$ & 0.000 \\
\hline Total cholesterol $(\mathrm{mg} / \mathrm{dl})$ & $94.03 \pm 27.86$ & $80.00 \pm 22.78$ & 0.002 \\
LDL cholesterol $(\mathrm{mg} / \mathrm{dl})$ & $30.51 \pm 5.75$ & $44.36 \pm 5.22$ & 0.000 \\
HDL cholesterol $(\mathrm{mg} / \mathrm{dl})$ & $204.00 \pm 98.46$ & $153.42 \pm 99.07$ & 0.002 \\
\hline Triglyceride $(\mathrm{mg} / \mathrm{dl})$ & & & \\
\hline
\end{tabular}

LDL- Low density lipoprotein, HDL- High density lipoprotein

Table-VII

Comparison of individual in-hospital outcome between two groups ( $n=271)$

\begin{tabular}{lcccc}
\hline Individual in-hospital & \multicolumn{2}{c}{ Groups } & Total(n=271) & $\mathrm{P}$ \\
\cline { 2 - 3 } outcome & $\begin{array}{c}\text { Group I(n=226) } \\
\mathrm{n}(\%)\end{array}$ & $\begin{array}{c}\text { Group II(n=45) } \\
\mathrm{n}(\%)\end{array}$ & $\mathrm{n}(\%)$ & \\
\hline Heart failure & $53(23.5 \%)$ & $4(8.9 \%)$ & $57(21.0 \%)$ & 0.029 \\
Arrhythmia & $35(15.5 \%)$ & $2(4.4 \%)$ & $37(13.7 \%)$ & 0.049 \\
Heart block & $18(8.0 \%)$ & $2(4.4 \%)$ & $20(7.4 \%)$ & 0.409 \\
Cardiogenic shock & $28(12.4 \%)$ & $1(2.2 \%)$ & $29(10.7 \%)$ & 0.044 \\
Cardiac arrest & $20(8.8 \%)$ & $3(6.7 \%)$ & $23(8.5 \%)$ & 0.631 \\
Death & $14(6.2 \%)$ & $1(2.2 \%)$ & $15(5.5 \%)$ & 0.287 \\
\hline
\end{tabular}

\section{Discussion:}

The study was intended to assess association of HDL cholesterol with in- hospital outcome of patients with acute coronary syndrome. Among the total 271 patients with ACS, we found that $226(83.4 \%)$ patients had low HDL cholesterol level. Roe et al. (2008) found that among NSTE-ACS patients, $18.1 \%$ had very low \& $34.5 \%$ had low $\mathrm{HDL}$ cholesterol level, which is a bit lower than our finding. Our study revealed that among total patients, total number of male patients was more than total number of female patients (72.7\% vs $27.3 \%)$. Our observation was supported by AlRasadi et al. (2011), (77\% vs $23 \%$ ) and Faizal et al. 2009) ( $80.63 \%$ vs $19.37 \%)$. We found that chest pain was the most common presentation in both groups of patients. The difference in presentation with chest pain between two groups was not statistically significant $(65.5 \%$ vs $51.1 \%, p=$ 0.068 ). However, significantly higher number of patients of group I presented with breathlessness than patients of group II $(33.6 \%$ vs $8.9 \%, p=0.001)$. Conversely, significantly more number of patients of group II presented with chest discomfort than patients of group I $(44.4 \%$ vs $28.3 \%$, $\mathrm{p}=0.033$ ). Our findings were supported by Khan and Mojumder (2009). Our study revealed that the difference in the history of smoking, hypertension, diabetes mellitus \& family history of CAD were not statistically significant. The observation of the current study was supported by the findings of Khan \& Mojumder (2009), Al-Rasadi et al. (2011), Manurung (2006), Faizal et al. (2009).

Our study showed that haemodynamic status was poor in patients of group I. The mean pulse rate of group I was significantly higher than patients of group II $(p=0.005)$. There were no statistically significant difference in mortality, cardiac arrest and development heart block between two groups ( $p>0.05)$. Any complication developed in $168(74.3 \%$ ) patients in group I and $13(28.9 \%)$ patients in group II. Patients of group I significantly developed more complications than group II $(p<0.001)$. The mean \pm SD hospital stay of group I patients was significantly higher than patients of group II ( $6.65 \pm 2.04$ vs $5.09 \pm 1.44$ days, $p<0.001)$. These findings were supported by the findings of Al-Rasadi et al. (2011), Faizal et al. (2009), Wolfram et al. (2006), Xavier et al. (2008) and Wilson (1990). Al- Rasadi et al. (2011) found that low HDLC was associated with higher all-cause mortality and cardiogenic shock, compared with the satisfactory HDL-C group. The impact of low HDL-C on other in-hospital outcomes (re-infarction, re-ischaemia, congestive heart failure) was not significant. Faizal et al. (2009) studied 253 ACS patients and found that 41 patients were died with mortality rate of $16.21 \%$. 


\section{Study limitation:}

Sample size was relative small.

The study was conducted in a tertiary care hospital which does not represent the general population of the whole country.

Regression analysis was not done. So, outcome might be influenced by confounding variables.

The study was conducted in a single centre.

\section{Conclusion:}

The current study has showed that ACS patients with low HDL-cholesterol have poor in-hospital outcome than those with normal HDL-cholesterol level. Heart failure, arrhythmia, cardiogenic shock and duration of hospital stay were found to be significantly more prevalent in ACS patients with low HDL-cholesterol group. This study may provide the basis for large further studies aiming in-hospital outcome analysis in ACS patients with low and normal HDL-cholesterol levels. We hope that the current study will also help in making planning strategies for better management of ACS patients with low HDL-cholesterol level.

Conflict of Interest - None

\section{References:}

1. Pinto'X, Mill'an J, MunozAet al. A very high prevalence of low HDL-C in Spanish patients with ACS. Clin Cardiol 2010; 33:418-423.

2. Murrary CJ and LopezAD. Mortality by cause for eight regions of the world: global burden of disease study. Lancet 1997; 349:1269-1276.

3. Khan AR and Majumder AAS. Study of Lipid Profile and Coronary Angiographic Pattern in Young Bangladeshi Patients with Acute Coronary Syndrome. Cardiovasc J 2009; 1:183-188.

4. Gonzalez-Porras JR, Martin- Herrero F, Garcia-Sanz R, Lopez ML, Balanzategui A, Mateos MV et al. Hyperhomocysteinaemia is a risk factor of recurrent coronary event in young patients irrespective to the MTHFR C677T polymorphism. Thromb Res 2007; 119:691-698.

5. Antman EM and Braunwald E. ST-elevation Myocardial Infarction: Pathology, pathophysiology and clinical features, In: Libby P, Bonow RO, Mann DL, Zipes DP, editors, Braunwald's Heart Disease, A Text Book of Cardiovascular Medicine, $8^{\text {th }}$ edition, Saunders Elsevier, Philadelphia, USA 2008;1210.

6. Barter PJ, Nicholls S, Rye KA, Anantharamaiah GM, Navab M, Fogelman AM. Anti-inflammatory properties of HDL. Circ Res 2004; 95:764-772.

7. Sacks FM. Expert Group on HDL cholesterol. The role of high density lipoprotein (HDL) cholesterol in the prevention and treatment of coronary heart disease: Expert group recommendations. Am J Cardiol 2002; 15:139-143.

8. Correia LC, Rocha MS, Esteves JP. HDL cholesterol level provides additional prognosis in acute coronary syndrome. Int J Cardiol 2009; 136:307-314.

9. Roe MT, Ou FS, Alexander KP et al. Pattern and prognostic implications of low HDL-C levels in patients with NSTEMI ACS. Eur Heart J 2008; 29:2480-2488.

10. Wolfram RM, Brewer HB, Xue Z, SAtler L, Pichard $A D$, Kent $K$ et al. Impact of Low High-Density Lipoproteins on In-Hospital Events and One-Year Clinical Outcomes in Patients With Non-ST-Elevation Myocardial Infarction Acute Coronary Syndrome Treated With Drug-Eluting Stent Implantation. Am J of Cardiol 2006; 98: 711-717.

11. Olsson AG, Schwarts GG, Szarek M et al. HDL but not LDL levels influence short term prognosis after ACS. Eur Heart J 2005; 26:890-896.

12. Enas EA, Garg A, Davidson MA, Nair VM, Huet BA, Yousuf S. Coronary heart disease and its risk factors in first generation immigrant Asian Indians to the United states of America. Indian Heart J 1996; 48:343-353. 